\title{
Impact of the Manager's Personality in the Pre-University Educational System
}

Veronica-Claudia ISTRATIE (ACHIM) ${ }^{1}$

\begin{abstract}
In the modern age, characterized by the emergence of the leader concept, it is necessary to study the importance and impact of the pre-university education of the manager who is not only a leader but must be a leader, a model to follow. In this article I will present the most important aspects of the study.

In essence, the research carried out in this paper aims to highlight the existence of a dependency relationship between factors such as human capital, the internal environment of the school on the one hand and the organizational performance on the other side.

The research carried out in this study aimed at designing a tool for measuring the impact of factors studied - defined as variables within the questionnaire, namely the impact of organizational culture on employees, organizational leadership and resilience to change.623
\end{abstract}

Keywords: leader, pre-university education, leadership, school performances.

JEL classification: M 00, M 12, M 52, M 54

DOI: $10.24818 /$ RMCI.2019.3.297

\section{Introduction}

From an epistemological point of view, this theme is very important for the current pre-university educational system. In an increasingly complex educational context, the need for a new type of leaders, educational managers to adapt as quickly and as quickly as possible to the variety of exigencies, but also to the multitude of social changes and the system of education as a whole. In addition, this new type of manager must be able to determine change among employees so that the school unit they lead can became an institution.

With a few exceptions, although the literature abounds in business strategy information, epistemology issues have been constantly ignored, especially as the interest of most specialists centered on the relationship between success stories and choice and the use of a set of instruments deemed to be sound and viable.

Although this inconvenience has now largely been overcome, it is still quite difficult to solve the problem of epistemology of processes, to determine the relevant

\footnotetext{
${ }^{1}$ Veronica-Claudia Istratie (Achim), Valahia University, Târgovişte

E-mail:veronique_claudia@yahoo.com
} 
aspects and concepts, to identify the issues that are really important and those that are only surface, superficial, the extent to which all these can reveal or generate positive results and regulatory proposals. (A. Ch. Martinet, 1990, p211)

The scientific approach is of particular significance from the perspective of the researcher's contribution to the development of the theory and managerial practice in the field, as a producer of scientific knowledge. The process of production, of scientific knowledge implies "an objective strategy of access to the real. The researcher must also try to explain those transformations of the world that have their source in the relationship of forces to the contextual interests. He must explain why such an evolution occurs earlier than another, in whose interests (M. Niculescu, N. Vasile, 2011, p15).

From this perspective, the issue of leadership in pre-university education is a fundamental research product, as it aims to produce new knowledge in a vital area for society, such as education management: phenomena and processes, formulation and hypothesis verification, conceptual models and theories.

The proposed scientific approach is positioned on the positivismconstructivism axis, if we consider (M. Niculescu, N. Vasile, 2011, pp 72-73):

- The object of knowledge (the reality considered objective, the perceived social facts and their reality versus reality) considered a product of human construction, the representations of the actors and the sense assigned to them by reality,

- The formation of knowledge (by observing objective reality, by experiencing versus knowledge is a construction of the subject resulting from interaction with the subject of the research), knowledge is an incremental process,

- Nature of knowledge (objective versus subjective),

- The knowledge method (induction of the deduction, induction versus deduction), -the object-subject link (independent of the interdependence).

\section{Research methodology}

The proposed scientific approach seeks to argue, on a scientific basis, the existing relationship between the leadership style of pre-university education managers - as formal leaders - their personality and the extent to which these leaders can influence employees in order to achieve organizational change.

In this context, the need for a fuller knowledge of the particularities of the leaders and the way in which they can influence the functioning and adaptation of the school as an organization to the school and social exigencies of the beneficiaries - pupils appears to be imperative (O. Nicolescu, I. Verboncu, 2001, p44).

The research has started by choosing the topic, consulting the literature, according to the original purpose and the central objective that I have proposed. It must also be specific that this study is exploratory, non-interventional, and constant. Its ultimate goal was to create a model of an educational leader that would meet all the attributes necessary for the educational context so varied in the present society.

Considering the performance models proposed by the literature, it is considered that there are a multitude of factors that have a particular impact on 
organizational performance in a school entity. Of course, taking into account the nature and specifics of the activities carried out within them, the approach is of a qualitative nature.

As a result, the research aimed at identifying those factors that have an impact on organizational performance. These were educational leadership, organizational culture and change. These factors were selected as a result of studying the performance models developed by the literature. Thus, based on Edgar Schein's model of organizational change (E. Schein, 2004, p123), it was proposed to outline a factorial efficient manager model (MEF) within the pre-university education units in Gorj County.

The scientific approach started in the first phase with a survey among teachers and school managers in order to identify their perceptions of the place and conditions of work, the work climate, the satisfaction they felt, and also perception of the external environment of the school. The survey was conducted by disseminating questionnaires on four major themes:

- identification the personality type,

- analyze the influence of the organizational culture on the employee,

- assessment of driving style,

- resistance to change

Based on the survey, the satisfaction of teachers in pre-university education schools, the importance of the educational act, their relations with the external partners of the school (local community, parents), leadership in the Romanian school were evaluated. The information gathered in this way was later used to identify whether or not the organizational performance of the school was determined by the variables defined in the questionnaire.

The research undertaken by questioning the teachers was correlated with the research done among the school managers, highlighting the significant aspects. Consequently, we have been looking at how workplace satisfaction influences organizational performance and the extent to which increased satisfaction is reflected in increased performance.

Demonstration of the dependency relationship was achieved by correlating the results obtained, following evaluations made by teachers and school managers through the questionnaire.

In parallel with the demonstration of the causal relationship between the determinants and the organizational performance, it was intended to perform some analyses and comparisons regarding the variables investigated through the questionnaire, respectively the extent to which they influence each other, or, on the contrary, the high degree of independence of some the variables considered.

The research tools used in this study were: California Personality Inventory (CPL), Self-assessment of leadership style, Organizational Culture Questionnaire The influence of organizational culture on the employee.

The CPI and the managerial style questionnaire were applied only to managers, and the other two questionnaires were applied both to school managers and employees with mirror-type questions. 


\section{California Inventory of Personality (C.P.I.)}

CPI was designed and experimented by Harrison H. Gough (1951), adapted and calibrated on the population of Romania by Babeş-Bolyai University, ClujNapoca in 1995.

CPI has been structured to evaluate daily variables used by people in everyday life to understand, classify, or predict their own behavior or others. Based on the use of terminology or folk-concepts derived from interpersonal relationships that are specific to each cultural environment, the California Personality Inventory seeks to build personality portraits, easy to decipher.

Numerous researches generated by the ICC have justified its utility, regardless of the socio-cultural environment in which it was used, subject to rigorous intercultural adaptation.

The scale adaptation and validation action started from the F / M scale, which aims at following three objectives:

- gender differentiation;

- the distinction between normal and sexually active persons;

- the distinction of a personality syndrome, which has a masculinity at the pole, and the other femininity.

Apart from the aspects related to the actual validity of the scales, it is questionable about the validity, the veracity of the answers provided by the respondents.

There are some specific ways that most people respond to a questionnaire of this type. For example, most people answer almost all, or even all items, there are very few items that are not answered. Deviations from general responses tend to affect the validity of information, jeopardizing the correctness of interpretation, and sometimes leading to erroneous conclusions.

Generally, the profile is considered normal, however there are three types of response behavior that can lead to invalidation of the protocol:

a) Positive Distortion: The evaluated person tries to present himself in a positive light;

b) Negative Distortion: The evaluated person tries to present a strongly negative image;

c) Random answer: The evaluated person provides random answers without taking into account the meaning of the items.

The inventory consists of 27 scales:

- Dominance (Do) (36 items) - social dominance;

- Capacity status (Cs) (28 items) - qualities associated with a particular social status;

- Sociability (Sy) (32 items) - openness and communication;

- Social presence (Sp) (36 items) - self-safety and balance;

- Self-acceptance (Sa) (28 items) - identification and appreciation of its own value;

- Independence (In) (28 items);

- Empathy (Em) (38 items) - orientation and understanding of others; 
- Responsibility (Re) (36 items);

- Socialization (So) (46 items) - the degree of acceptance and internalization of norms;

- Auto control (Sc) (38 items);

- The favorable impression (Gi) (40 items) - the impression it creates for others;

- Community $(\mathrm{Cm})(38$ items) - measure / degree of conventionality;

- Health (Wb) (38 items) - the physical and mental state of the person;

- Tolerance (To) (32 items) - tolerance, patience, prejudice;

- Achieving through conformism (Ac) (38 items) - functioning in an organized system

- Independence (Ai) (36 items) - functioning in a liberal system;

- Intellectual efficiency (Ie) (42 items);

- Psychological Intuition (Py) (28 items) - differentiation between thinking and feeling;

- Flexibility (Fx) (28 items) - identifies one pole, resistance to change, fluidity and the pleasure of changing others;

- Femininity / Masculinity (F / M) (32 items) - Evaluates male and female characteristics;

- Managerial Potential (Mp) (34 items) - organizational, coordination and control capacity;

- Work Orientation (Wo) (40 items) - identifies those individual characteristics, specific to integration / non-integration into working life;

- Creative Temperament (Ct) (42 items) - is designed to measure creativity in school, research and other fields.

- V1 (34 items) - indicates orientation towards extroversion / introversion;

- V2 (36 items) - indicates behavior with favorable / unfavorable orientation to norms;

- V3 (58 items) - indicates self-realization and fulfillment, scale distributed on 7 levels;

Scale 1 and V2 give 4 types:

- alpha - extroverted and accepting social norms;

- beta - introverted and accepting social norms;

- gamma - extroverted and rejecting social norms;

- delta - introverted and rejecting social norms.

In addition, the authors grouped the scales into the following dimensions:

- Relationship with others: scales: Do, Cs, Sy, Sp, Sa, In, Em.

- Self-management: Re, So, Sc, Gi, Cm, Wb, To scales.

- Motivation and style of thinking: Av, Ai, In.

- Personal features: Py, Fx, M / F scales

- Labor-related indicators: scales: $\mathrm{Mp}, \mathrm{Wo}, \mathrm{Ct}$ 
The California Personality Inventory was used in this study to develop the psychological profile of managers.

Relationship with others

On the Dominance scale (Do), the investigated managers obtained an average of $m=57.85$, indicating a level of medium-high dominance. Thus, they are characterized as responsible, sure and persuasive, task-oriented, without neglecting the human factor.

However, the standard deviation of Stdev $=8.109$, as well as the other descriptive indices, shows that the answers were somewhat inhomogeneous, varying quite a bit. However, with a few exceptions, the majority of subjects were in medium-high scores.

On the Status Capacity (Cs) scale, the average of $\mathrm{m}=57.72$ also reveals higher-to-medium scores, the subjects considering themselves ambitious, with a wide variety of interests and desire for success, who want a lifestyle comfortable, both material and social. The standard deviation of Stdev $=5.795$ also shows some scatter of the answers, but to a lesser extent than in the previous scale.

On the Sociability scale (Sy), the average of $\mathrm{m}=57.62$ indicates a high level of sociability, that is, the investigated managers are mostly socially oriented, sociable and extroverted, feel comfortable between people and in unusual social situations, are optimistic and have of social skills. The standard deviation of Stdev $=6.874$ indicates a certain lack of homogeneity, but most of the scores are at a higher average level of sociability, which means that it characterizes the features I have mentioned above.

On the Social Presence (Sp) scale, the average of $m=57.69$ indicates that the investigated managers are versatile and self-confident, looking for and needing social recognition, spontaneous, and difficult to tangle, like to be called, to hear audiences. Even if in this case the standard deviation is Stdev $=8.101$, the minima and maximums, as well as the individual scores, showed that many of the subjects achieved high scores on this dimension.

On the Self-Acceptance scale $(\mathrm{Sa})$, the average obtained by subjects of $\mathrm{m}=$ 57.41 and the standard deviation of Stdev $=6.869$ indicates that managers have a high degree of self-confidence, but without exaggeration, they are convincing in what they say like to speak in public, have the ability to assert and express their own value and the qualities they possess.

On the Independence scale (In), the average of $m=56.81$ indicates a moderate level, which is characterized by a fairly high degree of originality and inventiveness, the questioned managers are determined, but sometimes they may seem distant and arrogant. They need independence in decision-making, they also need to "move freely" in social and professional contexts.

On the Empathy $(\mathrm{Em})$ scale, the average of $\mathrm{m}=56.99$ shows that the investigated managers are empathic, they know and are willing to listen to others, have good social skills, are pleasant in conversation, have the ability to understand others. However, both the media and other descriptive statistical indicators show some dispersion of the subjects' responses but also some moderation in terms of 
empathy, being within normal limits, with no major risk of increasing the emotional and emotional transfer, which may have a high degree of subjectivity and therefore non-functional.

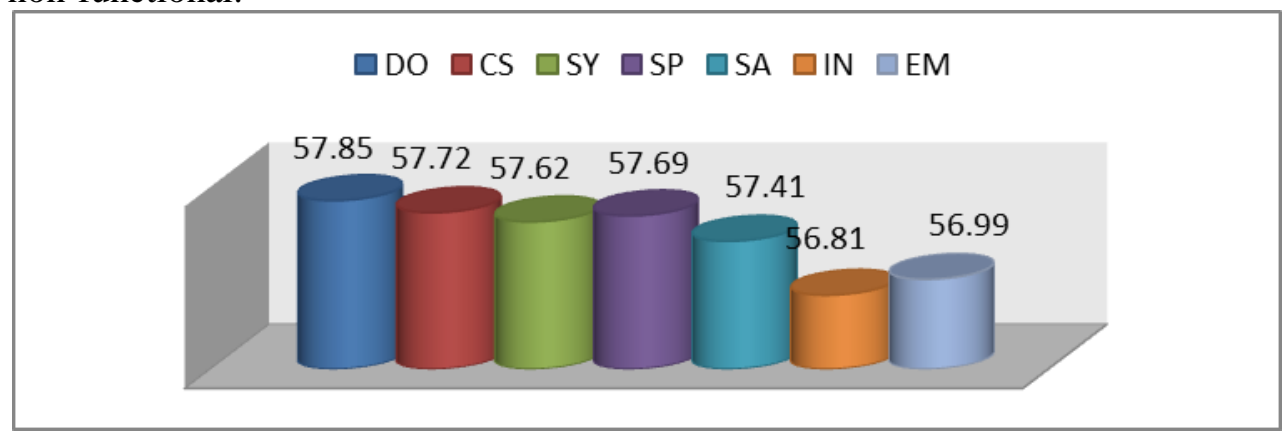

Figure 1. Mediums obtained by subjects

in the C.P.I. - scales Do, Cs, Sy, Sp, Sa, In, Em

Therefore, with regard to the relationship with others, most subjects (with few exceptions) achieved high scores, indicating both the interest of managers for employees and the availability and ability to properly communicate with them.

\section{Self-management}

On the Responsibility $(\mathrm{Re})$ scale, the average obtained by subjects of $\mathrm{m}=$ 57.30 indicates that they are conscientious, loyal, carry out their duties and tasks at the end, are caring for the others and conscientious.

On the socialization scale (So), the average of scores of $m=53.07$ shows that managers have relatively well internalized social norms, with scores averaging. Although they generally know and respect the rules, this is not done overly, most of the respondents harmoniously combining traditional and innovative strategies that do not necessarily follow a pre-established, classic pattern. Investigated managers are also open to new, to non-conformism, but to the extent that they do not detract from the operation of the organization.

On the Auto control $(\mathrm{Sc})$ scale, the mean $\mathrm{m}=57.52$ indicates a medium-high level of self-control of subjects. They are cautious, think before they act, evaluate the situations in their organization, but without being overly typing, have the ability to control their emotions and anger, even when they are under pressure or in problematic situations, are proud of the fact that they self-discipline and adapts to various situations.

On the Good impression (Gi) scale, the average of $m=58.27$ indicates that the subjects have a good impression of their own person, they are caring about those around them, being largely concerned. About the well-being of the employees, are polite and quite compliant with the rules, norms and values of the organization, take care of their own image within the organization and at the level of society.

On the Communality scale $(\mathrm{Cm})$, the average of $m=57.19$ shows that managers have a medium-high degree of practical sense, are effective, but to a 
certain extent predictable, do not perceive themselves as very different from others, which many times, it is a positive thing, being perceived as popular employees, as people with whom any problem can be discussed.

On the Well $(\mathrm{Wb})$ scale, the average score was $m=58.29$, with a standard deviation of Stdev $=7.777$, indicating a high status of the subjects. This state of wellbeing translates into satisfaction with the everyday situations faced by the subjects; they are cheerful and have a favorable physical and emotional state of health, they feel competent in solving their professional and living situations.

Although the standard deviation is quite early, the analysis of individual scores indicated that most of the investigated managers had a high level of well-being, with only a few of them achieving lower scores.

On the Tolerance scale (Tol), the average of $\mathrm{m}=57.13$ shows a mediumhigh level, which means that managers generally respect the rights and convictions of others, try to understand and accept them with all their peculiarities, are reasonable, are impartial.

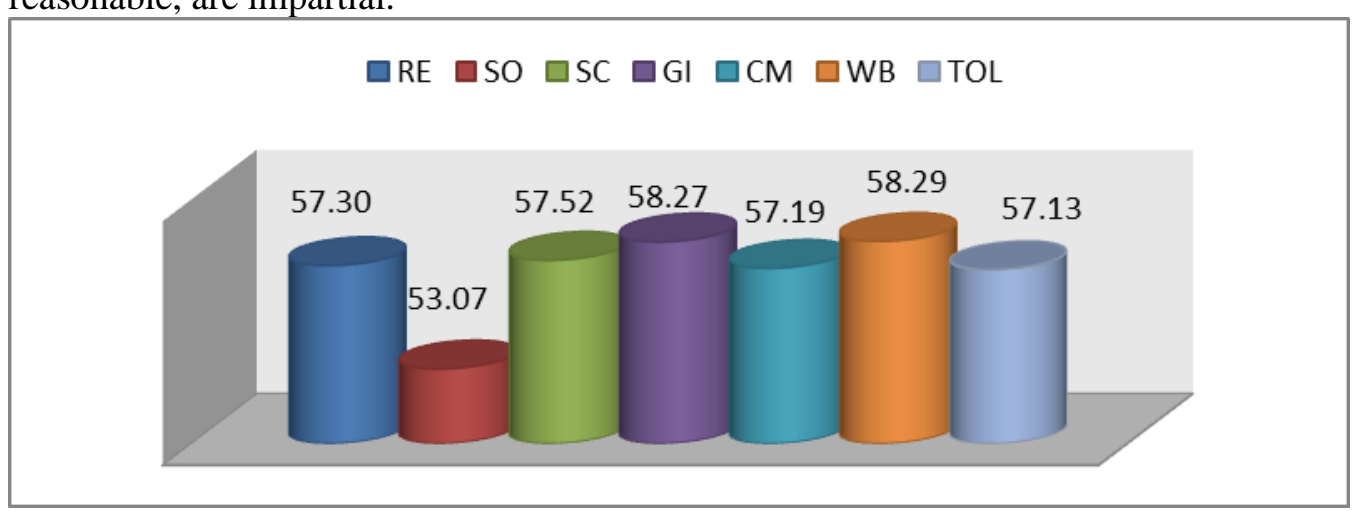

Figure 2. Environments obtained by subjects

in the C.P.I. - the scales Re, So, Sc, Gi, Cm, Wb, Tol

So, with regard to self-management, the subjects have proven that they can properly manage their own behavior and their own emotions about themselves and others, are relaxed, tolerant, and balanced without, however, going to the extreme.

\section{Motivation and style of thinking}

On the Conformity Acquisition (Ac) scale, the average of $\mathrm{m}=57.57$ indicates that managers are working well in an organized and normative setting, have clear objectives and are geared towards achieving the goals they are doing, are effective in their work.

On the Independence Realization (Ai) scale, the average of $\mathrm{m}=57.57$, shows that managers are doing the same in a less structured, looser, lighter framework. They have initiative and are independent, are able to define their own goals, they allow degrees of freedom, even in more normative systems and situations. 
On the Intellectual Efficiency scale (Ie), the average of $m=57.98$ shows that the subjects are intellectually efficient, confident and comfortable in academic, intellectual and conceptual situations, have verbal fluency, are convincing, think before to take a certain action or to make a decision.

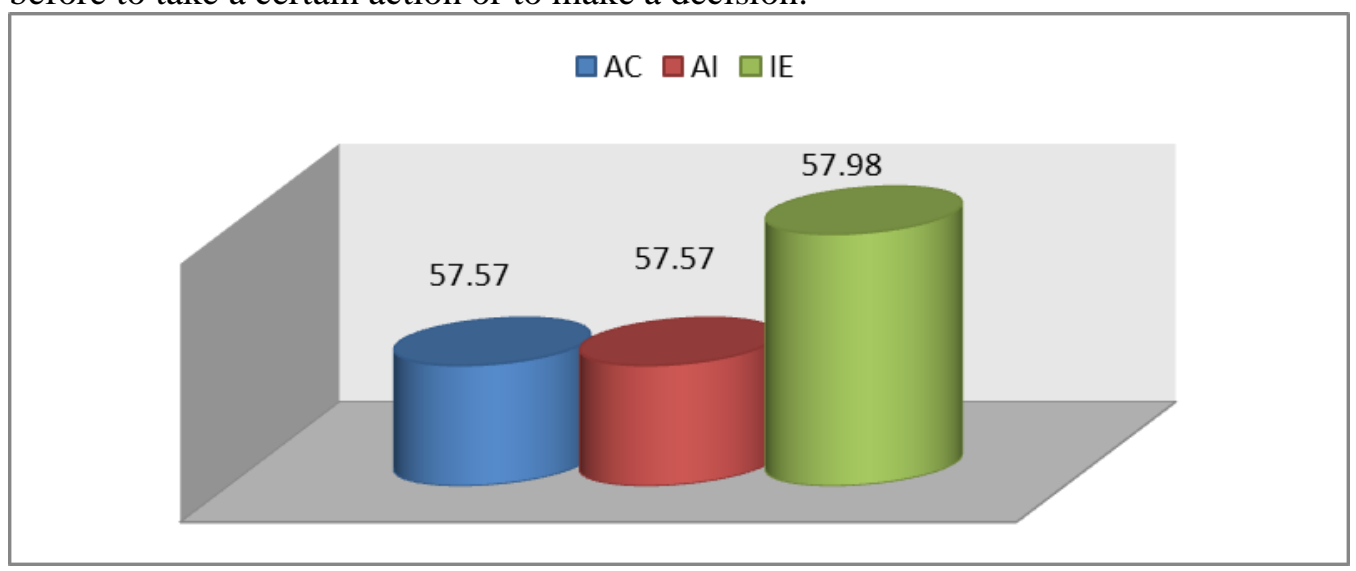

Figure 3. Environments obtained by subjects in the C.P.I. - Ac, Ai, Ie scales

So, in terms of motivation and style of thinking, managers are efficient and flexible in different working environments.

\section{Personal characteristics}

On the Psychological Intuition (Py) scale, the average of $\mathrm{m}=57.93$ indicates that the surveyed managers are analytical, are concerned about the expectations, motivations and emotions of employees, they quickly make impressions on people and situations, most of the time correct, are sympathetic, sociable and warm with the others.

On the Flexibility scale $(\mathrm{Fx})$, the average of $\mathrm{m}=55.25$ indicates an average level. Thus, although they like variety and change, managers included in the study also work in a routine context, finding alternative resources and rapidly thinking about issues and situations in various organizational and life contexts.

On the Masculinity / Femininity (M / F) scale, the mean of $\mathrm{m}=55.25$ shows that subjects, irrespective of gender / gender, combine the two characteristics, balance between them. Thus, interviewed managers are sensitive to others' feelings, but also focused on action when needed. They need to assert themselves, to lead, to be leaders. 


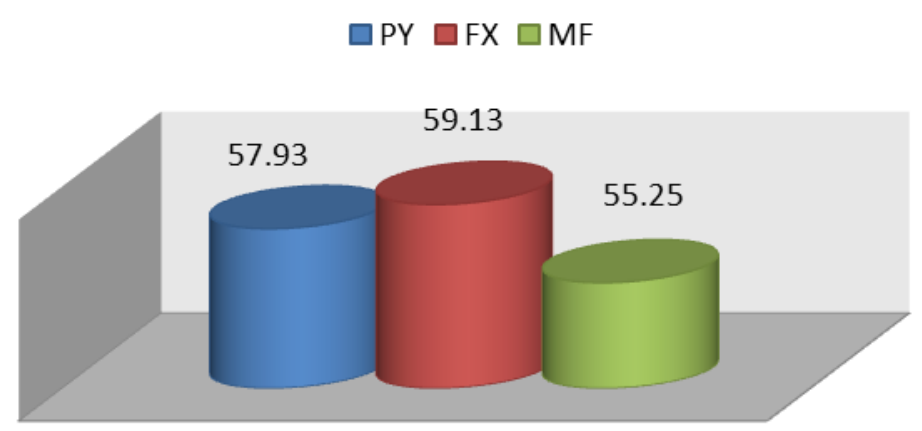

Figure 4. Mediums obtained by subjects in the C.P.I. - scales Py, Fx, M / F

Hence, on the dimension of personal characteristics, the investigated subjects, in most cases, have proven themselves to have personal skills to certify them as formal (educational) leaders of educational institutions.

\section{Indicators related to work}

On the Managerial Potential (Mp) scale, the average of $m=58.97$ shows that most subjects are effective in working with people, have good ability to take appropriate decisions, control organizational situations, share credit with others, have the ability to motivate people and explain rules and norms, when appropriate.

On the Work Orientation scale (Wo), the average of $m=58.51$ indicates a good anchoring of managers in their work, dedication, they are trusted people, with high ideals and who accept the professional challenges without complaining.

On the Creative Potential $(\mathrm{Ct})$ scale, the average of $\mathrm{m}=56.45$ reveals that the subjects have free thinking, which harmoniously blends the conventional with the unconventional, are quick and creative.

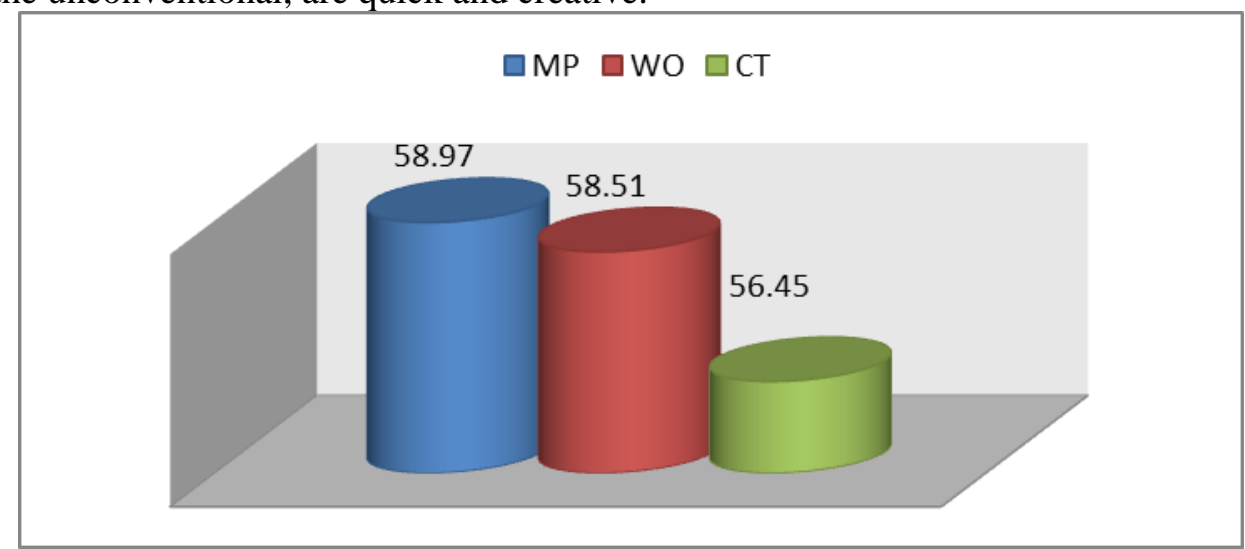

Figure 5. Environments obtained by subjects in the C.P.I. - scales Mp, Wo, Ct 
So, in terms of job-related indicators, managers' scores show that they have the necessary attitude to take on leadership roles.

Psychological types

The analysis of $\mathrm{V} 1$ and $\mathrm{V} 2$ vectors (determined as a result of item responses) led to the following types of managers:

Table 4. Statistical indices of vectors $\mathrm{V} 1$ and $\mathrm{V} 2$

\begin{tabular}{lllll}
\hline & & Frequency & Percent & $\begin{array}{l}\text { Valid } \\
\text { Percent }\end{array}$ \\
\hline \multirow{2}{*}{ Valid } & Alpha & 23 & 15.3 & 15.3 \\
& Beta & 9 & 6.0 & 6.0 \\
Delta & 9 & 6.0 & 6.0 \\
Gamma & 109 & 72.7 & 72.7 \\
Total & 150 & 100.0 & 100.0 \\
\hline
\end{tabular}

Vector V3 - Feeling of the self-realization

Table. 5. Statistical index of V3 (average, median, standard deviation, variance)

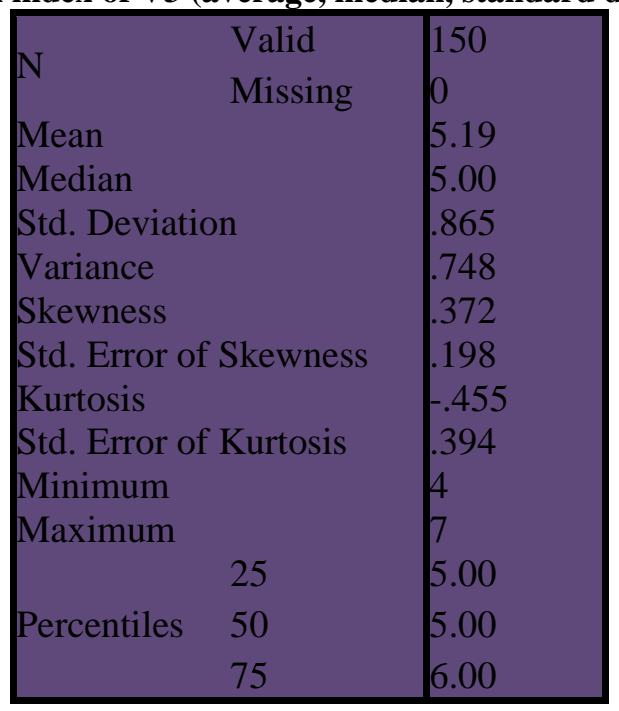

Table 6. Statistical indexes of version V3 (frequency, percentage)

\begin{tabular}{llllll}
\hline & Frequency & Percent & $\begin{array}{l}\text { Valid } \\
\text { Percent }\end{array}$ & $\begin{array}{l}\text { Cumulative } \\
\text { Percent }\end{array}$ \\
\hline Valid & 4 & 32 & 21.3 & 21.3 & 21.3 \\
& 5 & 69 & 46.0 & 46.0 & 67.3 \\
& 6 & 37 & 24.7 & 24.7 & 92.0 \\
7 & 12 & 8.0 & 8.0 & 100.0 \\
\hline
\end{tabular}


Regarding the feeling of personal fulfillment / personal and professional satisfaction, research data showed that the majority of respondents are satisfied with the intellectual and professional level they reached.

It can be seen that most managers are on the upper levels of comfort given by their personal fulfillment. And the fact that most of those investigated are at level 5 of self-realization can be a good thing, and it will continue to act to achieve personal goals and the organizations they lead.

However, it seems that the managers included in this study have the skills they need for a leader with balanced personality structures, being open to new, flexible, versatile, and task-oriented but very leaning toward people, inventive and innovative, but consistent with the goals of the organizations lead.

Table 7. Statistical indicators following the application of C.P.I.

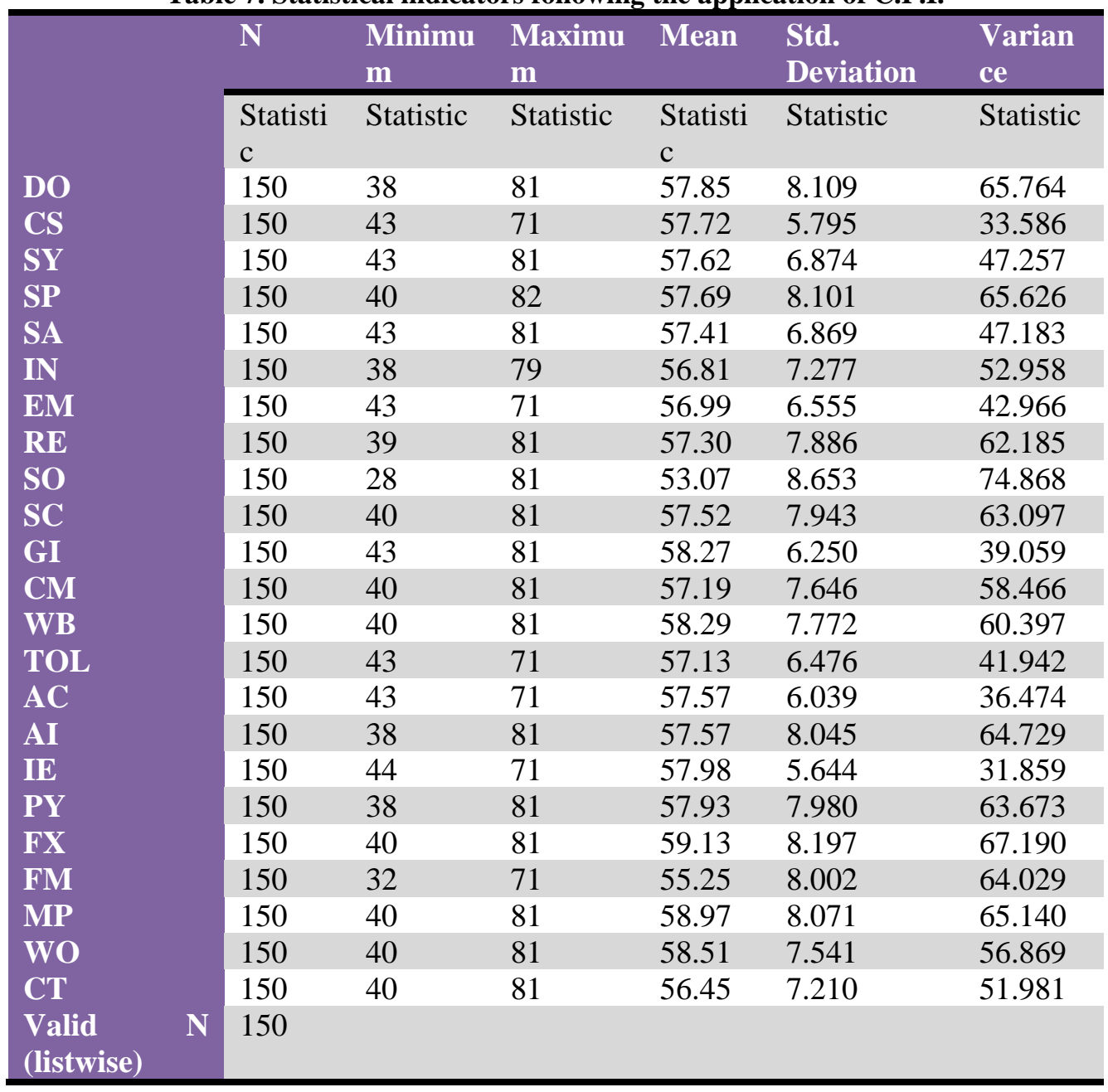

$308 \quad$ Volume 20, Issue 3, July $2019 \quad$ Review of International Comparative Management 
Table 8. Statistical indices - frequency, mean, median, mode, following CPI application (Do, Cs, Sy, Sp, Sa, In, Em)

\begin{tabular}{|c|c|c|c|c|c|c|c|c|}
\hline & & DO & $\mathrm{CS}$ & SY & SP & SA & IN & EM \\
\hline $\mathrm{N}$ & Valid & 150 & 150 & 150 & 150 & 150 & 150 & 150 \\
\hline & Missing & 0 & 0 & 0 & 0 & 0 & 0 & 0 \\
\hline Mean & & 57.85 & 57.72 & 57.62 & 57.69 & 57.41 & 56.81 & 56.99 \\
\hline Median & & 58.00 & 58.00 & 57.00 & 57.00 & 57.00 & 56.00 & 57.00 \\
\hline Mode & & 58 & 61 & 55 & 61 & $55 \mathrm{a}$ & $52 \mathrm{a}$ & $55 \mathrm{a}$ \\
\hline Std. Deviati & & 8.109 & 5.795 & 6.874 & 8.101 & 6.869 & 7.277 & 6.555 \\
\hline Percentiles & 25 & 53.00 & 53.75 & 53.00 & 52.00 & 52.00 & 52.00 & 52.00 \\
\hline & 50 & 58.00 & 58.00 & 57.00 & 57.00 & 57.00 & 56.00 & 57.00 \\
\hline & 75 & 62.25 & 61.00 & 61.25 & 62.00 & 62.00 & 61.00 & 61.00 \\
\hline
\end{tabular}

Table 9. Statistical indices - frequency, mean, median, mode after application of CPI (So, Sc, Gi, Cm, Wb, Tol, Ac, Ie, Py, Fx, FM)

\begin{tabular}{|c|c|c|c|c|c|c|c|c|c|c|c|c|c|}
\hline & & $\mathrm{SO}$ & $\mathrm{SC}$ & GI & $\mathrm{CM}$ & WB & TOL & $\mathrm{AC}$ & AI & IE & PY & $\mathrm{FX}$ & FM \\
\hline \multirow[t]{2}{*}{$\mathrm{N}$} & Valid & 150 & 150 & 150 & 150 & 150 & 150 & 150 & 150 & 150 & 150 & 150 & 150 \\
\hline & Missin & 0 & 0 & 0 & 0 & 0 & 0 & 0 & 0 & 0 & 0 & 0 & 0 \\
\hline \multirow[t]{2}{*}{ Mean } & & 53.0 & 57.5 & 58.2 & 57.1 & 58.2 & 57.1 & 57.5 & 57.5 & 57.9 & 57.9 & 59.1 & 55.2 \\
\hline & & 7 & 2 & 7 & 9 & 9 & 3 & 7 & 7 & 8 & 3 & 3 & 5 \\
\hline \multirow[t]{2}{*}{ Median } & & 52.5 & 57.0 & 58.0 & 57.0 & 58.0 & 57.0 & 58.0 & 57.0 & 58.0 & 57.0 & 58.0 & 56.0 \\
\hline & & 0 & 0 & 0 & 0 & 0 & 0 & 0 & 0 & 0 & 0 & 0 & 0 \\
\hline Mode & & 51 & 58 & 61 & $55 a$ & 58 & 61 & 61 & 58 & 61 & 55 & 58 & 55 \\
\hline Std. & & 8.65 & 7.94 & 6.25 & 7.64 & 7.77 & 6.47 & 6.03 & 8.04 & 5.64 & 7.98 & 8.19 & 8.00 \\
\hline Deviation & & 3 & 3 & 0 & 6 & 2 & 6 & 9 & 5 & 4 & 0 & 7 & 2 \\
\hline \multirow{6}{*}{$\begin{array}{l}\text { Percentile } \\
\mathrm{S}\end{array}$} & 25 & 48.0 & 52.0 & 55.0 & 52.0 & 53.0 & 52.0 & 53.0 & 52.0 & 54.0 & 52.0 & 54.0 & 49.7 \\
\hline & & & 0 & 0 & 0 & 0 & & & & & & & \\
\hline & 50 & 52.5 & 57.0 & 58.0 & 57.0 & 58.0 & 57.0 & 58.0 & 57.0 & 58.0 & 57.0 & 58.0 & 56.0 \\
\hline & & & 0 & 0 & 0 & 0 & 0 & & 0 & 0 & & & 0 \\
\hline & 75 & 58.0 & 62.0 & 61.2 & 62.0 & 63.0 & 61.0 & 61.0 & 62.0 & 61.0 & 63.0 & 66.0 & 61.0 \\
\hline & & & 0 & 5 & 0 & 0 & 0 & h & 0 & 0 & 0 & 0 & \\
\hline
\end{tabular}


Table 10. Statistical indices - frequency, mean, median, mode following application of CPI (Mp, Wo, Ct scales)

\begin{tabular}{|ll|l|l|l|}
\hline & & MP & WO & CT \\
\hline N & Valid & 150 & 150 & 150 \\
Mean & Missing & 0 & 0 & 0 \\
Median & & 58.97 & 58.51 & 56.45 \\
Mode & & 58.00 & 58.00 & 56.00 \\
Std. Deviation & 67 & 58 & 61 \\
& 25 & 5.071 & 7.541 & 7.210 \\
Percentiles & 50 & 58.00 & 54.00 & 51.00 \\
& 75 & 66.00 & 58.00 & 56.00 \\
& & 63.00 & 61.00 \\
\hline
\end{tabular}

\section{Conclusions}

Innovation in the management system in education resides in its characteristics, because:

- Innovation proposes a measurable improvement (increasing the level of education of the population, the results, the school attendance rate, the educational achievements obtained by pupils at different exams, national and / or international tests etc.);

- Innovation must be sustainable (decentralization of education);

- Innovation must be a deliberate action that contributes to the school success of as many individuals as possible (extending the compulsory schooling period, which manages to maintain in the school system and school at risk of school dropout, educational programs for inclusion in the education system people with disabilities, the socio-economically and socially disadvantaged, adults, etc.).

The process of change in education and the development of a new model of a manager must start from the awareness of the necessity of change and from the continuation of the manifestation of the desire for change, which implies the accumulation of the necessary knowledge, the formation of new competences, the stabilization of the system and the sustainable development. Only in this way can the management and management in education change, and new managerial objectives may emerge. 


\section{References}

1. A. Ch. Martinet (coord.), Epistemologies and Sciences of Management, Ed. Economica, Paris, 1990

2. JF Le Ny J, Méthode "in Bloch $\mathrm{H}$ et al (sans le direction de) Fundamental Dictionary of Psychology", Ed. Larousse, Paris, 1997

3. L. Vlăsceanu, Introduction to Methodology of Social Research Ed. Polirom, Bucharest, 2013

4. M. Niculescu, N. Vasile, Epistemologie, perspectivă interdisciplinară, Ed. Bibliotheca, Târgoviște, 2011

5. M. Richelle, Experimentation, method in Doron R, Parot F. (under direction) Psychology Dictionary, Ed Humanitas, 1999

6. M. Zlate, Introduction to Psychology, Polirom Publishing House, Iasi, 2015

7. O. Nicolescu, I. Verboncu, Metodologii manageriale, Ed. Tribuna Economică, București, 2001

8. R. Mucchielli, L'observation psychologique et psychosociologique, ESF, Paris, 1974

9. Schein, Edgar H. Organizational culture and leadership / Edgar H. Schein.-3rd ed. p. cm.-(The Jossey-Bass business \& management series), San Francisco, 2004 